\title{
Charge Location Directs Electron Capture Dissociation of Peptide Dications
}

\author{
Yury O. Tsybin, Kim F. Haselmann, Mark R. Emmett,* \\ Christopher L. Hendrickson, ${ }^{*}$ and Alan G. Marshall* \\ Ion Cyclotron Resonance Program, National High Magnetic Field Laboratory Florida State University, \\ Tallahassee, Florida, USA
}

The effect of peptide dication charge location on electron capture dissociation (ECD) fragmentation pattern is investigated. ECD fragmentation patterns are compared for peptides with amide and free acid C-terminal groups. ECD of free acid compared with C-terminally amidated peptides with basic residues near the $\mathrm{N}$-terminus demonstrates increased formation of $a$-type ions. Similarly, ECD of free acid compared with C-terminally amidated peptides with basic residues near the $\mathrm{C}$-terminus exhibits increased formation of $\mathrm{y}$-type ions. Alteration of the peptide sequence to inhibit the formation of charged side chains (i.e., amino acid substitution and acetylation) provides further evidence for charge location effect on ECD. We propose that formation of zwitterionic peptide structures increases the likelihood of amide nitrogen protonation (versus basic side chains), which is responsible for the increase in $a$ - and y-type ion formation. (J Am Soc Mass Spectrom 2006, 17, 1704-1711) (C) 2006 American Society for Mass Spectrometry

$\mathrm{D}$ issociation of multiply charged peptide cations by interaction with electrons in the gas-phase, referred to as electron capture dissociation (ECD) [1], mainly results in formation of $c$ - and $z$-type fragment ions [2,3] (Reaction 1):<smiles></smiles><smiles>[R]C(C)C(=N)O</smiles><smiles>[R]CC(=O)CCCC</smiles>

Significantly lower yield of $a$ - and $y$-type ions is observed in some cases, but has not been a subject of systematic studies (Reaction 2):

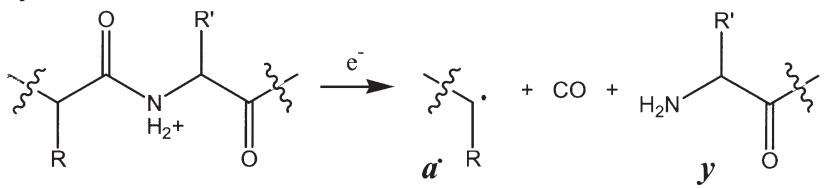

Budnik et al. [4] attempted to derive additional sequence information based on fragment ion relative abundances. In that study, the correlation of $c$ - and $z$-fragment ion abundances in ECD of the peptide, Substance $\mathrm{P}$, in its C-terminal amidated and free acid forms was surprisingly high relative to collisioninduced dissociation (CID), and the only reported differences were side-chain losses and the charge-reduced

Published online September 11, 2006

Address reprint requests to Dr. A. G. Marshall, Ion Cyclotron Resonance Program, National High Magnetic Field Laboratory, Florida State University, 1800 East Paul Dirac Drive, Tallahassee, FL 32310-4005, USA. E-mail: marshall@magnet.fsu.edu

* Also at the Department of Chemistry and Biochemistry, Florida State University, Tallahassee, FL 32306, U.S.A. species. That study did not report any differences in $a$-ions and was performed with a directly heated filament. Subsequent technique development [5-8] increased ECD efficiency and tandem mass spectrometry sensitivity.

Preferential formation of $a$ - and $x$-type ions has recently been noted for interaction of peptide anions with energetic electrons $(>10 \mathrm{eV})$ in electron detachment dissociation (EDD [9]. Pronounced differences between EDD fragmentation patterns of amide and free-acid forms reveal preferential formation of $x$-type ions in the free-acid peptides [10]. The proposed explanation favored deprotonation of the carboxylic acid versus the amide group because of typically $\sim 70 \mathrm{~kJ}$ $\mathrm{mol}^{-1}$ higher gas-phase acidity of primary amides compared to carboxylic acid $[10,11]$. Conceivably, one can also expect differences in ECD of peptide dications with different C-terminal groups.

Here, we report distinct differences in the ECD fragmentation pattern with regard to $a$ - and $y$-type ions of amidated versus free-acid forms of peptide dications. Formation of $a$ - and $y$-type ions was systematically evaluated for a set of synthetic peptides with different $\mathrm{N}$ - and C-terminal groups.

\section{Methods}

\section{Sample Preparation}

Synthetic peptides were obtained from Sigma (Sigma Aldrich, St. Louis, MO), American Peptide Company (Sunnyvale, CA), or synthesized in house by Fmocsolid-phase peptide synthesis and used without further 
purification. The peptides include amidated, free-acid, methyl ester, and fragments of Substance P (Arg-ProLys-Pro-Gln-Gln-Phe-Phe-Gly-Leu-Met), luteinizing hormone releasing hormone (LHRH) as well as a set of specifically designed amino acid sequences in amide and free acid forms including pGlu-Pro-Lys-Pro-GlnGln-Phe-Phe-Gly-Leu-Met, Arg-Pro-Lys-Pro-Gln-GlnPhe-Phe-Gly-Leu-Cys, Lys-Leu-Leu-Leu-Leu-Pro-LeuLeu-Leu-Leu, Lys-Leu-Leu-Leu-Leu-Leu-Pro-Leu-LeuLeu, and Lys-Leu-Leu-Leu-Leu-Lys-Leu-Leu-Leu-Leu. Peptides were dissolved in water and acetonitrile mixture (50:50 vol $/ \mathrm{vol}$ ) with addition of $0.1 \%$ formic acid to a final concentration of about $1 \mathrm{uM}$. The gas-phase basicity of some peptides was decreased by acetylation: $2 \%$ pure acetic anhydride was added to electrospray solution before analysis. Acetylation of different sites was controlled by $\mathrm{pH}$ : at slightly acidic $\mathrm{pH}$, only low pKa sites were acetylated, e.g., the N-terminus; at near-neutral $\mathrm{pH}$, intermediate sites were acetylated, e.g., $\mathrm{N}^{\varepsilon}$-Ac of Lys1 in $\mathrm{KL}_{4} \mathrm{KL}_{4}$; and at basic $\mathrm{pH}$, all sites were acetylated [12].

\section{Fourier Transform Ion Cyclotron Resonance Mass Spectrometry}

Experiments were performed with a homebuilt $9.4 \mathrm{~T}$ FT-ICR mass spectrometer [13]. Ions were generated in the external microelectrospray ion source with a flow rate of $\sim 300 \mathrm{~nL} / \mathrm{min}$ [14]. After 1 to $2 \mathrm{~s}$ accumulation in the external octopole ion trap $(4.8 \mathrm{~mm}$ i.d., $15 \mathrm{~cm}$ long, $300 \mathrm{~V}_{\mathrm{p}-\mathrm{p}}$ at $1.5 \mathrm{MHz}$ ), ions were transported by a radiofrequency octopole ion guide $(4.8 \mathrm{~mm}$ i.d., $160 \mathrm{~cm}$ long, $150 \mathrm{~V}_{\mathrm{p}-\mathrm{p}}$ at $1.5 \mathrm{MHz}$ ) into an open-ended cylindrical ICR trap (94 mm i.d., $300 \mathrm{~mm}$ long). Gated ion trapping was employed without cooling gas. Precursor ion selection was performed in the external quadrupole mass filter or in the ICR trap by stored waveform inverse Fourier transform (SWIFT) excitation [15]. Subsequently, a $10 \mathrm{~mm}$ diameter electron beam (1-100 ms) was injected into the ICR trap followed by an electron clean-up event $(100 \mathrm{~ms})$ [16]. The cathode potential during electron injection was $-5 \mathrm{~V}$ and kept at $+10 \mathrm{~V}$ otherwise. Accelerating grid voltage was at $+5 \mathrm{~V}$ during electron injection and at $-200 \mathrm{~V}$ otherwise. A multiple-pass electron injection regime was employed (transfer octopole DC offset $-60 \mathrm{~V}$ ). Product ions were allowed to cool for $100 \mathrm{~ms}$ before frequency-sweep excitation (72 to $720 \mathrm{kHz}$ at $150 \mathrm{~Hz} / \mu \mathrm{s}$ ) followed by broadband detection (555 ms detection period, $512 \mathrm{~K}$ word data). The time-domain transient signal was baseline corrected, Hanning apodized, zero-filled, and Fourier transformed to produce a magnitude-mode frequency spectrum that was converted to a massto-charge ratio spectrum by the quadrupolar approximation [17, 18]. Data acquisition was performed by use of a Predator data station and data analysis with MIDAS 3.21 software [19].

For cross-correlation comparison of product ion relative abundances between different tandem mass spec-

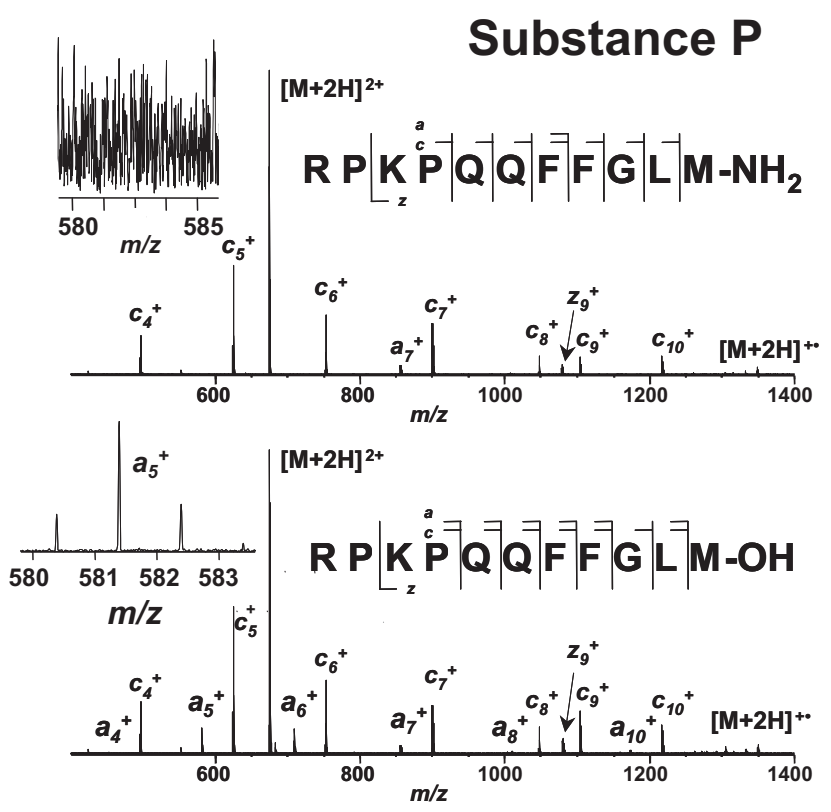

Figure 1. ECD FT-ICR mass spectra of Substance P in amide form (top) and free acid form (bottom).

tra, the ion relative abundances were first normalized to the total fragment ion abundance in a given tandem mass spectrum. The correlation coefficients, $R$, were then calculated to quantitatively estimate the similarity between product ion spectra. The correlation coefficient is given by [4]:

$$
R=\frac{\sum_{i}\left\{\left(x_{i}-\bar{x}\right)\left(y_{i}-\bar{y}\right)\right\}}{\left[\sum_{i}\left\{\left(x_{i}-\bar{x}\right)^{2} \sum_{i}\left(y_{i}-\bar{y}\right)^{2}\right\}\right]^{1 / 2}},
$$

in which $\mathrm{x}$ and $\mathrm{y}$ represent relative abundances for two fragmentation patterns. The correlation coefficient is high for similar product ion spectra, with a maximum value of one for comparison of the same product ion spectra.

\section{Results and Discussion}

\section{ECD of Free-Acid Versus Amide Forms of Substance P}

Figure 1 shows ECD FT-ICR mass spectra of Substance $\mathrm{P}$ with different $\mathrm{C}$-terminal groups (amide and freeacid). The most striking difference between the spectra is the fivefold higher total relative abundance of $a$-type ions for the free-acid form of Substance P (see Table 1). For example, the ratio of $a_{5}$ ions to $c_{5}$ ions is 0.18 for free-acid Substance P versus 0.00 for the amide form. Side-chain losses are similar to those previously reported [4].

Cross-correlation coefficient calculations yielded an expected $R=0.78$ value for $c$-ions from the amide and free-acid forms of Substance $P$ and $R=0.04$ for the corresponding $a$-ion comparison. These values demon- 
Table 1. Product ion relative abundances and correlation coefficients for ECD FT-ICR MS of specified peptides

\begin{tabular}{|c|c|c|c|c|c|c|c|c|c|}
\hline \multirow[b]{2}{*}{ Sequence } & \multirow{2}{*}{$\begin{array}{l}\text { Ion } \\
\text { Type }\end{array}$} & \multicolumn{7}{|c|}{ Ion Relative Abundance by Cleavage Site } & \multirow[b]{2}{*}{$\mathrm{R}$} \\
\hline & & 4 & 5 & 6 & 7 & 9 & 9 & 10 & \\
\hline Substance P-OH & c & 16 & 48 & 24 & 15 & 8 & 14 & 10 & 0.78 \\
\hline Substance $\mathrm{P}-\mathrm{NH}_{2}$ & c & 20 & 56 & 30 & 26 & 9 & 9 & 10 & \\
\hline Substance $\mathrm{P}-\mathrm{OH}$ & a & - & 0.25 & 8.60 & 8.40 & 3.00 & 0.60 & 1.20 & 0.04 \\
\hline Substance P- $\mathrm{NH}_{2}$ & a & - & - & - & - & 4.50 & - & - & \\
\hline pGlu-substance P- $\mathrm{OH}$ & c & 18.0 & 36.0 & 30.0 & 16.5 & 15.0 & 32.0 & 28.0 & 0.75 \\
\hline pGlu-substance P- $\mathrm{NH}_{2}$ & c & 15.0 & 39.0 & 32.0 & 21.5 & 12.0 & 18.0 & 34.0 & \\
\hline pGlu-substance $\mathrm{P}-\mathrm{OH}$ & a & 0.90 & 9.00 & 8.50 & 2.15 & 1.60 & 1.00 & 0.90 & 0.53 \\
\hline pGlu-substance P- $\mathrm{NH}_{2}$ & a & 1.00 & 2.10 & 1.80 & 2.10 & 2.00 & 1.00 & 0.80 & \\
\hline KL4KL4- OH & a & - & 1.10 & 1.70 & 0.40 & 0.35 & 1.95 & - & 0.37 \\
\hline KL4KL4- $\mathrm{NH}_{2}$ & a & - & 0.40 & 0.50 & 0.30 & 1.40 & 2.10 & - & \\
\hline Ac-KL4KL4- OH & a & - & - & 1.60 & 0.50 & - & 1.85 & - & 0.96 \\
\hline Ac2-KL4KL4- OH & a & - & - & 0.50 & 0.20 & - & 0.90 & - & \\
\hline Ac3-KL4KL4- OH & a & - & 0.80 & 1.05 & 1.45 & 0.20 & 0.20 & - & \\
\hline
\end{tabular}

strate good correlation with previously published $c$-ion correlation coefficients (reported average value of 0.8 for ECD) [4] and expose a distinct difference between $a$-ion formation from ECD of amidated and free-acid forms of Substance P. The low abundance of $z$-type ions (only $z_{9}$ is observed) and the absence of $y$-type ions after ECD of Substance $\mathrm{P}$ are attributed to the basic residues (primarily Arg and Lys) near the N-terminus (so that the product ion charge site is almost always on an N-terminal fragment).

\section{Charged Amino Acid Residue at the C-Terminus; y-Ion Formation}

ECD FT-ICR MS of luteinizing hormone releasing hormone (LHRH) dications in which an Arg residue is the third amino acid from the C-terminus (pEHWSYGLRPG) exhibits no $a$-ions, but pronounced differences in $y$-ion products between the amide and the free acid forms (Figure 2). Reaction pathway 2 forms $a^{\prime} / y$-ions, but only fragment ions having basic residues at their respective terminus appear in the spectrum. Therefore, for Substance $\mathrm{P}$ (with basic residues at the $\mathrm{N}$-terminus) $a$-ions appear in the free acid form whereas the free acid form of LHRH (with basic residues at the $\mathrm{C}$-terminus) yields $y$-ions. Interestingly, ECD of LHRH results in formation of $x_{9}$ ion (cleavage $\mathrm{N}$-terminal to His) in both amide and free acid forms of the peptide.

\section{The Effect of Decreased Basicity of the N-Terminus}

Blocking the free N-terminal amine-group with pyroglutamic acid (pGlu) reduces the possibility of a positively charged N-terminus. Furthermore, because the $\mathrm{N}$-terminal amino acid (e.g., Arg in Substance P) is replaced by the pGlu residue, the guanidino group with the highest gas-phase basicity (GB) of any amino acid residue $(\mathrm{GB}=10.3 \mathrm{eV})$ [20] is also removed. The gas-phase basicity of pyroglutamic acid is not known (to our knowledge), but GB of Gln is $9.3 \mathrm{eV}$ and GB of $\mathrm{N}$-methyl-acetamide is $9.2 \mathrm{eV}$ [21]. The preferential charge sites of the modified Substance P dications are therefore Lys at the third position and somewhere along the backbone near the C-terminus due to Coulombic repulsion from the Lys. The ECD fragmentation pattern of the amide form of pGlu-peptide contains mostly c-type ions and is very similar to that for Substance P with a correlation coefficient of 0.58 (data not shown). The correlation coefficient for the $c$-ions between pGlu-Pro-Lys-Pro-Gln-Gln-Phe-Phe-Gly-LeuMet- $\mathrm{NH}_{2}$ and pGlu-Pro-Lys-Pro-Gln-Gln-Phe-Phe-GlyLeu-Met-OH is 0.75 (Table 1), nearly the same as
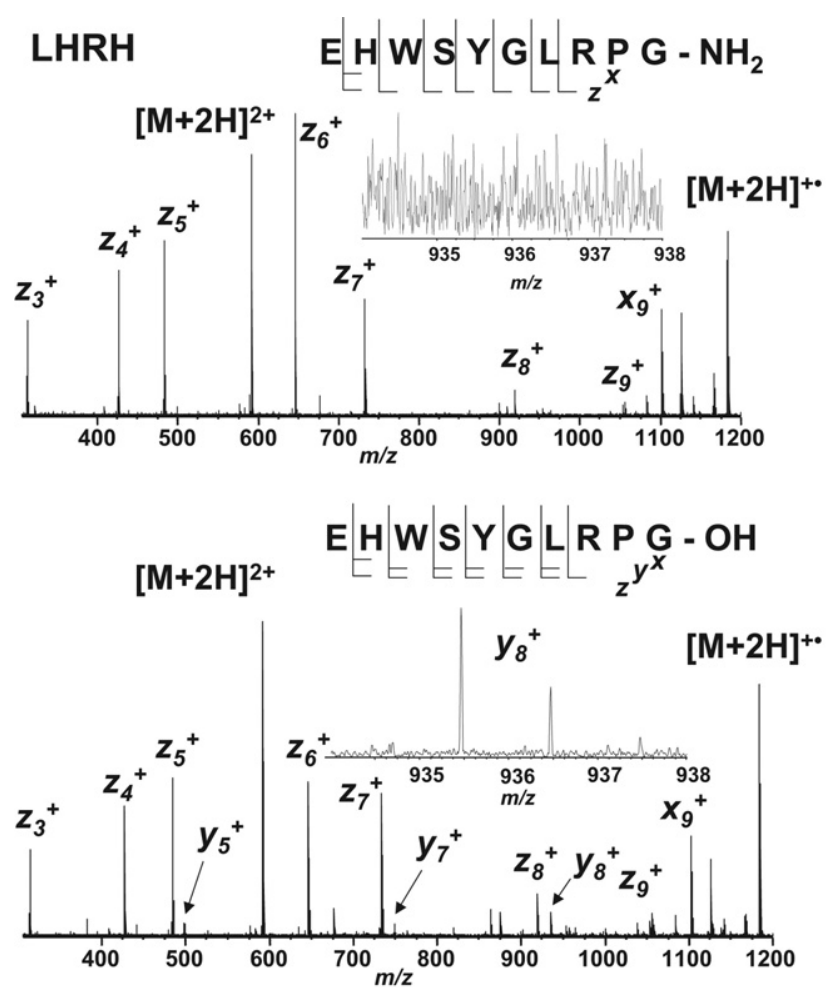

Figure 2. ECD FT-ICR mass spectra of luteinizing hormone releasing hormone (LHRH) in amide form (top) and free acid form (bottom). 
between the corresponding amide and free acid forms of Substance P. Formation of $z$-type ions is not favored either, with the sole exception of $z_{9}$ as in Substance $P$ for which the charge can reside on Lys.

As for amide and free acid forms of Substance P, ECD of the free acid form of the N-terminally modified peptide produced $a$-type ions in higher relative abundance than for the amide form (Table 1). The ratio of $a$-type ions to $c$-type ions was 0.06 for the amidated pGlu-peptide and more than twice as high (0.14) for the free-acid peptide. In particular, the ratio of $a_{5}$ ion to $c_{5}$ ion is 0.06 for the amidated form and more than four times higher (0.25) for the free-acid form. For $a$-ion formation, the correlation coefficient between amidated and free acid forms of the pGlu-peptide is higher $(R=$ 0.53 , Table 1) than for Substance P $(R=0.04$, Table 1$)$. Removing the N-terminus arginine and thereby decreasing gas-phase basicity (by at least $1 \mathrm{eV}$ ) of the pGlu-modified form of Substance P relative to unmodified Substance P increases $a$-ion formation.

\section{Acetylation of Free Amine Groups}

Taking into account the influence of decreased basicity and the location of protons, we probe the effect of the free amine groups by acetylation. Under acidic conditions, only the N-terminus is acetylated and approximately the same abundance of $a$-ions is observed in the ECD mass spectrum of Substance P (data not shown) of the acetylated free acid form relative to the unmodified form $\left(a_{5} / c_{5}=0.19, a_{7} / c_{7}=0.19\right.$, and the R-value for $a$-ion correlation with the free acid form is 0.95 ). Because ECD was unaffected by blockage of the $\mathrm{N}$ terminus amine group, it is thus not charged. Blockage of all free amine groups in Substance $\mathrm{P}-\mathrm{OH}$ (N-terminus and the Lys3 side-chain) results in 30\% higher abundance of all $a$-ion fragments (relative to all products) than for the singly acetylated species $\left(a_{7} / c_{7}=0.35\right.$ and the $a$-ion correlation with the free acid form drops, $R=$ 0.85). Furthermore, Lys3 is no longer charged, because the $z_{9}$-ion is absent. Because of the reduced gas-phase basicity due to acetylation, protons are more likely to reside on amide nitrogens. Here, the $a_{3}+1$ fragment is observed, $\left(a_{3}+1 / c_{7}=0.17\right)$, consistent with protonation N-terminal to Pro.

Another example of the influence on $a$-ion formation in the free acid versus the amidated form and its acetylated derivatives is provided by ECD of the synthetic peptide, Lys-Leu-Leu-Leu-Leu-Lys-Leu-Leu-LeuLeu: both the free acid and the amidated forms produce $a$-ions, although in different proportions (Figure 3) as reflected in their lower correlation coefficient; $R=0.37$. The difference in C-terminal group in this peptide, apparently, is less important for $a$-ion formation than for Substance P or LHRH. Acetylating the N-terminus has a profound influence: the number of observed $a$-ions decreases from five to three (Table 1). Further acetylation of the Lys1 $\left(\mathrm{Ac}_{2}-\mathrm{KL}_{4} \mathrm{KL}_{4}\right.$, under neutral conditions) does not change the correlation of $a$-ions

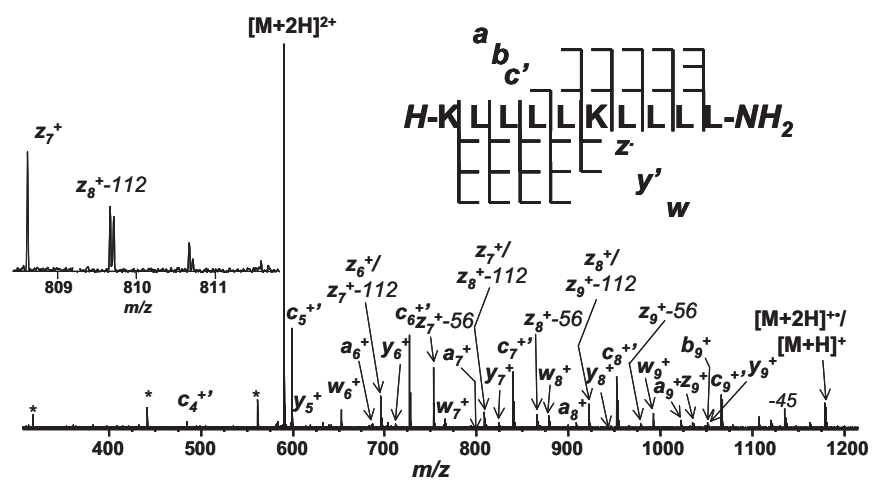

Figure 3. ECD FT-ICR mass spectra of the synthetic peptide, Lys-Leu-Leu-Leu-Leu-Pro-Leu-Leu-Leu-Leu in amide form (a), free acid form (b), and modified form (c), Lys-Leu-Leu-Leu-LeuLeu-Pro-Leu-Leu-Leu, showing a shift of the most abundant $a$-ion by one amino acid toward C-terminus.

relative to the mono-acetylated form $(R=0.96)$. Most likely, a charge is shared between the $\mathrm{N}$-terminus and the amine of Lys1. As a result, the a-ion appearance from the unmodified form changes, but only to a lesser extent for the monoacetylated form relative to the diacetylated form. Full acetylation (N-terminus plus both lysines) of this peptide increases the overall $a$-ion abundance again, highlighting the importance of the decreased gas-phase basicity that makes both protons available to occupy the backbone positions of both the carbonyl and the amide, leading not only to Reaction 1 , but also to Reaction 2. Charge location sites can be observed indirectly from side-chain losses from the free acid or amidated precursor ions. Here (data not shown), it can be noted that the underivatized free acid form (KLLLLKLLLL-OH) loses 17.021 Da, typical of free amine groups of the N-terminus and/or Lys; the underivatized amidated form loses $45.018 \mathrm{Da}$, corresponding to formamide (45.021 Da) from the C-terminus; the mono-acetylated form loses $59.031 \mathrm{Da}$, corresponding to acetamide (59.037 Da) from an acetylated N-terminus; both di- and triply-acetylated forms lose $43.014 \pm$ $0.0045 \mathrm{Da}$, equivalent to an acetyl loss (43.018 Da).

\section{The Role of Proline}

Gas-phase basicity plays a role in determining the charge location and ultimately the product ions. Proline introduces a backbone tertiary amide that has higher gas-phase basicity than a backbone secondary amide. If no amino acid residue with higher gas-phase basicity is present, that site should be protonated. In the model peptide, KLLLLPLLLL-OH, the highest GB site is on the Lys side-chain at the $\mathrm{N}$-terminus (or shared with the N-terminus free amine due to their close proximity) and the second site ought to be at Pro6.

ECD FT-ICR mass spectra of peptide, Lys-Leu-LeuLeu-Leu-Pro-Leu-Leu-Leu-Leu, in amide and free acid forms confirms a higher $a$-ion yield from peptide in free acid form (Figure 4, top, middle). The 45.016 Da loss 


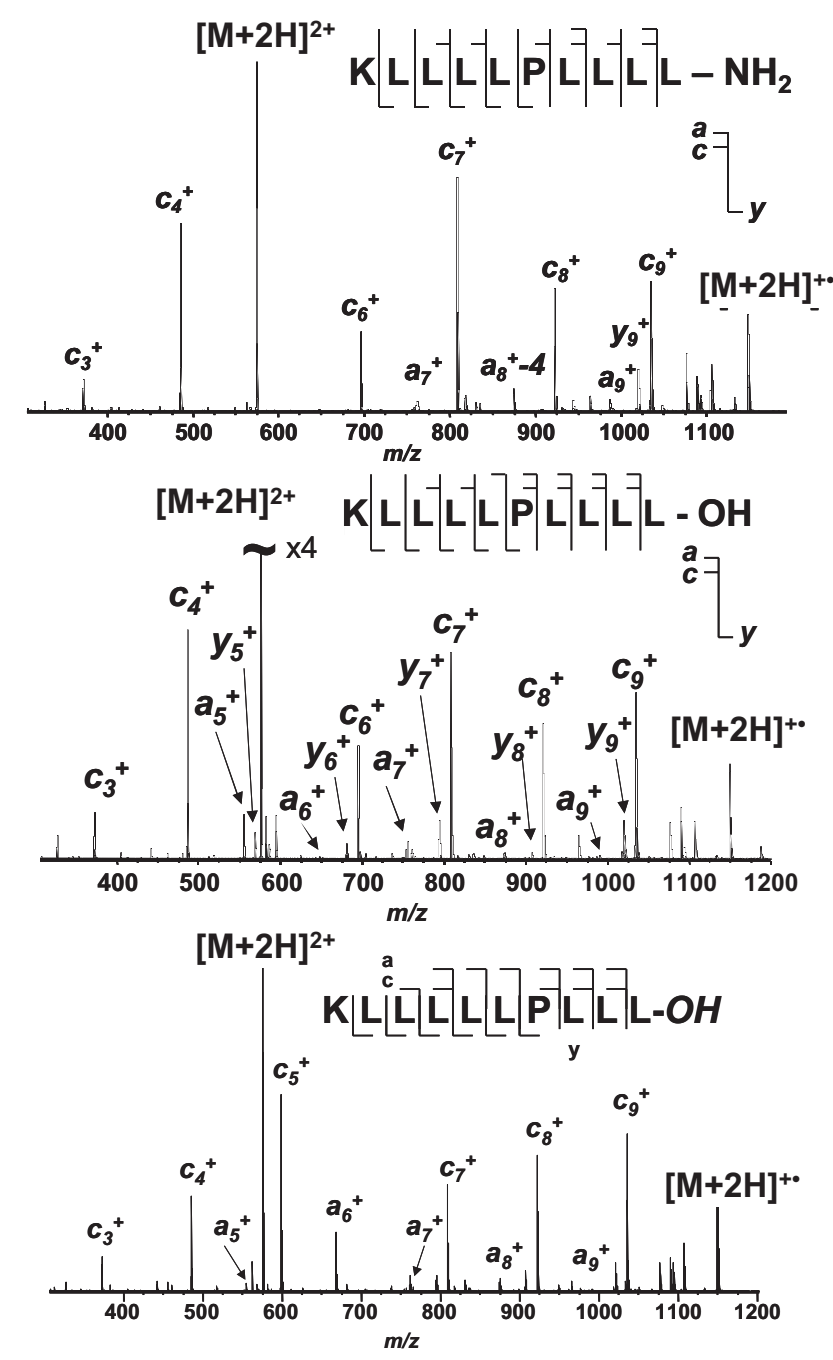

Figure 4. ECD FT-ICR MS of the synthetic peptide, Lys-Leu-LeuLeu-Leu-Lys-Leu-Leu-Leu-Leu- $\mathrm{NH}_{2}$. Asterisks denote electronic noise peaks.

(corresponding to formamide; incorporation of a hydrogen atom) from the charge-reduced, $[\mathrm{M}+2 \mathrm{H}]^{+}{ }^{\bullet}$, species in the amidated form and not in the free acid form reflects the C-terminus amide group solvation of the charge site. Correlation coefficients were 0.95 for $c$-ions, 0.23 for $a$-ions and 0.59 for $y$-ions. Among $a$-ions, the $a_{5}$ ion (cleavage N-terminal to Pro residue) is the most abundant in the free acid form (about 10 times more abundant than other $a$-ions), consistent with proton location at the Pro amide nitrogen. Movement of the Pro residue one amino acid toward the $\mathrm{C}$-terminus resulted in the expected shift of the most abundant $a$-ion one amino acid toward the C-terminus, i.e., $a_{6}^{+}$, Figure 4 , bottom. As a result, the correlation coefficient for $a$-ions between Lys-Leu-Leu-Leu-Leu-Pro-Leu-Leu-Leu-Leu and LysLeu-Leu-Leu-Leu-Leu-Pro-Leu-Leu-Leu is very low $(R<$ $0.2)$.

Interestingly, $y$-ions are more prevalent in the free acid form relative to the amide form (Figure 4, low abundance $y$-ions are not assigned). Formation of $y$-ions in the peptides shown in Figure 4 indicates that the charge can be retained at Pro. However, no $z$-ions were observed. Replacement of Pro6 with Lys6 (see above) resulted in expected higher yield of $a$-ions in the free acid form, but the $y$-ions were accompanied by abundant $z$-ions (Figure 3), demonstrating the difference between the two pathways in electron capture dissociation, as discussed below.

We hypothesize that Reaction 2 ( $a$ - and $y$-type product ion formation) can only be realized if the proton involved in neutralization is located on the amide nitrogen of the polypeptide backbone: protons situated at basic amino acids with high GB (e.g., Lys) will be solvated by the peptide backbone carbonyl oxygen leading to $c / z$ type ions (Scheme 1). Conversely, protonation directly on the backbone can either be at the carbonyl oxygen or at the amide nitrogen. Protonation of the amide nitrogen increases with certain substitutions, such as Pro: for the KLLLLPLLLL-OH peptide, abundant $a_{5}$ ions are observed (Figure $4 \mathrm{~b}$ ), immediately $\mathrm{N}$-terminal to the Pro residue. When the Pro residue is moved one position to the right in KLLLLLPLLL-OH, the most abundant $a$-ion moves accordingly $\left(a_{6}\right.$, Figure $4 \mathrm{c})$. The Pro represents a conformational change with the second highest GB (after Lys1) at the amide nitrogen in the polypeptide chain and if the proton resides there,

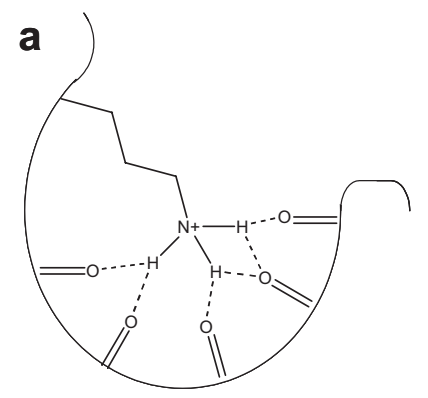

b

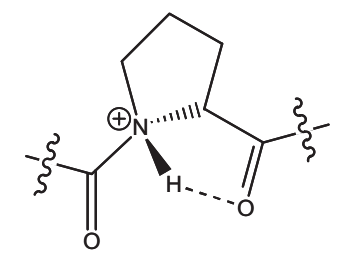

C<smiles>[Z6]C(=O)[NH+]1[CH]OC1[R]</smiles>

Scheme 1. Charge localizations that affect ECD fragmentation pattern; (a) general charge-solvated high proton affinity site e.g., Lys; (b) Pro charged at the amide nitrogen and stabilized by the nearby carbonyl oxygen; (c) protonation at the backbone amide nitrogen stabilized by the nearby carbonyl oxygen. 
$a$-ion formation is observed (Scheme 1). $N$-protonated sites in polyglycine can be found in analysis of gasphase basicities by Zhang et al. [22, 23] Although those sites have lower gas-phase basicity, they nevertheless could exist in forms where carbonyl solvation is less pronounced and influenced only by nearby carbonyl groups (Scheme 1).

\section{The Effect of Precursor Ion Charge State}

One difference between the amidated (or O-methylated) form and the free acid is the acidic nature of the carboxylic acid and the possibility of forming zwitterionic structures, a tendency more pronounced for peptides having residues with high gas-phase basicity (e.g., Arg). However, even if not a zwitterion, the free acid form removes one potential charge site and thus increases the probability of backbone amide protonation. Formation of a zwitterionic structure in dications creates three positive charges (protons) and one negative charge (carboxylate), resulting in a doubly charged species. ECD spectra of triply charged Substance P in the amidated and the free acid form (data not shown) are similar and the correlation coefficient for the singly charged $c$-ions is high $(R=0.99)$. $a$-Ions are observed for both forms with a correlation coefficient of 0.32 ; however, the most abundant fragment ions (again $a_{5}$ and $a_{6}$ ) are found in the amidated form (data not shown). The ratio of the $a_{5}$ ion abundance to the $c_{5}$ ion abundance is 0.10 for the amidated form and 0.05 for the free acid form. In fact, the correlation coefficient for $a$-ion formation between doubly charged Substance P in free acid form and triply charged Substance P in amide form is very high (0.73), suggesting similar protonation sites. In summary, the higher charge state resulted in $a$-ions from both forms (though less abundant) regardless of the C-terminus, because each additional charge increases the relative abundance of protonated backbone amides.

For larger polypeptide cations, the yield of $a$-ions increases with higher charge state; Breuker et al. [24] performed ECD of ubiquitin $(8565 \mathrm{Da})$ in different charge states, from $5+$ to $13+$, and found more $a / y$ fragment ions at higher charge states. Furthermore, Williams and coworkers [25] reported that the formation of $a$-type ions in ECD of an amidated polypeptide with multiple, evenly distributed Lys residues was not observed, even for higher charge states $(2+$ to $5+$ were analyzed). However, in that study the number of charges (protons) never exceeded the number of Lys residues.

\section{The Possible Effect of Zwitterionic Structure Formation}

Several factors play a role in the formation of stable $a$-type ions. First, formation of $\mathrm{N}$-terminal product ions requires that a charged residue be located near the

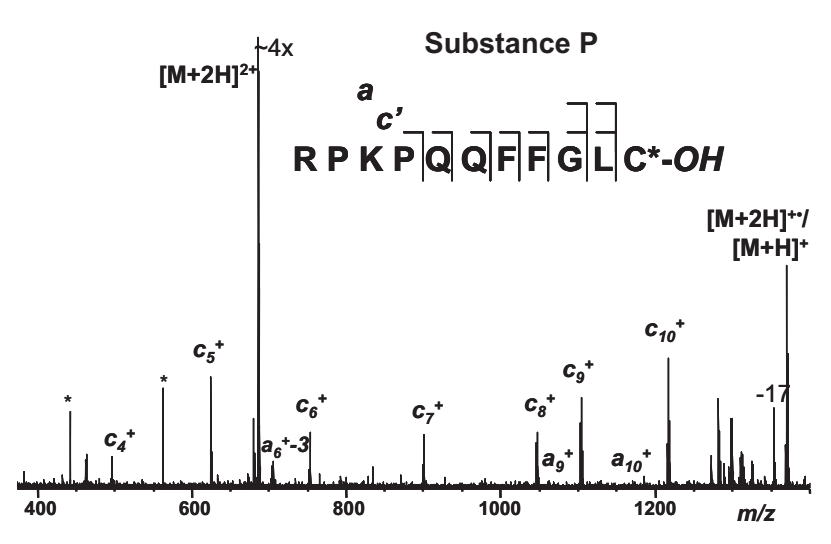

Figure 5. ECD FT-ICR MS of $H$-RPKPQQFFGLC $\left(\mathrm{SO}_{3} \mathrm{H}\right)-\mathrm{OH}$. Note the few and low abundance $a$-ions. Asterisks denote electronic noise peaks.

N-terminus (e.g., Arg, Lys). The second factor is the gas-phase basicity. As the basicity of the polypeptide decreases, the position of the charge becomes less distinct as the possible charge locations increase. Thus, in a polypeptide without highly basic amino acids (Arg, Lys and His), the charge (proton) may not only be solvated by the backbone but may be located directly on the backbone, at many possible sites. Moreover, as the charge state increases, the GB of the next protonation site decreases. Kaltashov and Fenselau [26] found that the gas-phase basicity of triply charged melittin decreased by $0.9 \mathrm{eV}$ relative to the doubly charged species, and between the first and second gas-phase basicity of des-Arg-bradykinin the decrease was even larger: 2.7 $\mathrm{eV}$ [27]. For higher charge states, the sites of protonation will involve less favorable sites on the backbone as well. Third, polypeptides that are able to form zwitterionic structures should favor $a$-ion formation. The $n$ charge state of a zwitterionic structure has $n+\mathrm{x}$ charges of the observed polarity and $x$ charges of opposite polarity. The ability of the doubly charged free acid form of Substance P (and to some extent others, preferentially those containing Arg) to produce abundant $a$-ions can now readily be explained from the higher charge state interpretation: the free acid form can participate in zwitterionic formation. Zwitterionic states require typically at least two highly basic sites and one acidic site, as in Substance P-OH [28]. We therefore believe that at least a fraction of the ion population of Substance $\mathrm{P}-\mathrm{OH}$ exists in the zwitterionic state, creating an extra proton that could occupy sites of lower GB leading to eq 2 .

To enhance the formation of zwitterionic structures with a stronger acid than the carboxylic acid, we synthesized a sulfonic acid derivative of Substance P, $H$-RPKPQQFFGLC $\left(\mathrm{SO}_{3} \mathrm{H}\right)-\mathrm{OH}$. The ECD FT-ICR mass spectrum of this derivative yielded only two very low abundance $a$-ions $(>0.5 \%)$, Figure 5 . The two most abundant $a$-ions in the underivatized peptide $\left(a_{5}-\right.$ and $a_{6}$-ions) were not present at all. Compared with the amidated form, the oxidized Cys-derivative does not decrease $a$-ion formation. The zwitterionic structure 


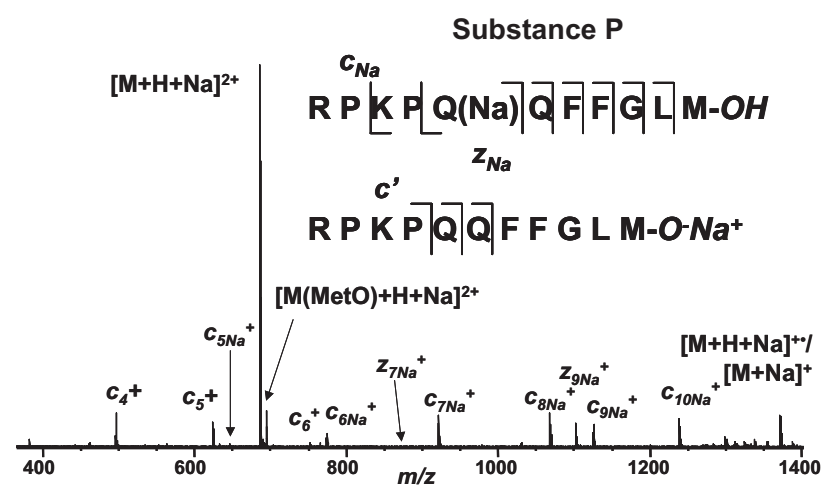

Figure 6. ECD FT-ICR MS of Substance P in its free acid form; [M $+\mathrm{H}+\mathrm{Na}]^{2+}$. The structures that produce $c^{\prime}-$ and $c_{\mathrm{Na}}$-ions are indicated along with their respective fragmentation patterns.

may be compared with the amidated form with little (or no) formation of $a$-ions (i.e., no extra proton available for $a$-ion formation). The strong acid did not produce more abundant $a$-ions; however, the absence of $z_{9}^{+}$ (compared with Figure 1, bottom) suggests that a zwitterion is formed. The counter charge is most likely located near the C-terminus and does not contribute to $a$-ion formation, as in Substance $\mathrm{P}-\mathrm{NH}_{2}$. Therefore, zwitterionic character alone is not a sufficient predictor of $a$-ion production.

\section{Alkali Metal Attachment Decreases N-Protonation and a-Ion Formation}

Examples in which the amide nitrogen is not protonated are provided by sodiated species: in the ECD mass spectrum of the $[\mathrm{M}+\mathrm{H}+\mathrm{Na}]^{2+}$ species of the free acid form of Substance P, no $a$-ions are observed (Figure 6). From the fragmentation pattern, sodium can be located at Gln5, the amino acid with the highest sodium ion affinity [29]. Williams and coworkers state that electron capture happens at the site with highest recombination energy (RE) [25]: from the proton affinity of $\operatorname{Arg}(10.6 \mathrm{eV})$ and the sodium cation affinity of $\mathrm{Gln}(2.2 \mathrm{eV})$, the recombination energy is 3.6 and $3.2 \mathrm{eV}$, respectively. The sodiated fragments are observed, however, and three protonated $c^{\prime}$ fragment ions are observed as well (not seen in the amidated form, data not shown). We postulate the presence of a second structure (at least to some extent): salt formation of the sodium cation and the C-terminal carboxylate anion leaves two protons for ionization of the Arg and Lys residues. Those protons can be solvated by the polypeptide backbone and lead to the conventional $c^{\prime}$-ions and the observed sodiated $z_{9}^{+}$-ion (suggesting that the Lys residue is charged). Therefore, in the $[\mathrm{M}+\mathrm{H}+$ $\mathrm{Na}]^{2+}$ species, the one to two protons available are not located or solvated by backbone amide nitrogen due to the higher gas-phase basicity of Arg/Lys and thus, the reaction pathway 2 is not observed. Furthermore, Williams and coworkers [25] did not find any $a$-ion fragments in $\mathrm{ECD}$ of $[\mathrm{M}+\mathrm{H}+\mathrm{Li}]^{2+}$ species, in which $\mathrm{M}=\mathrm{AcHN}-$
(AKAAK) ${ }_{3} \mathrm{~A}-\mathrm{NH}_{2}$, except for one $\left(a_{14}\right)$ constituting $0.5 \%$ of the total fragment ion abundance and it is protonated.

\section{Conclusions}

We have investigated the effect of charge distribution on the formation of $a$-ions and $y$-ions and demonstrated for the first time the pronounced influence of the C-terminal group and position of basic residues along the peptide backbone on the ECD fragmentation pattern of peptide dications. Increased yield of $a$-type fragment ions $\left(\mathrm{C}_{\alpha}-\mathrm{C}\right.$ backbone bond rupture) and $y$ type fragment ions ( $\mathrm{C}-\mathrm{N}$ backbone bond rupture) in ECD was dominant for free-acid peptide dications with basic residues preferentially located at the N-terminus or C-terminus, respectively. The total abundance of $a$-ions ( $y$-ions) is several times higher for peptides in free-acid form compared to the amidated peptides.

We suggest that enhanced a-type ion formation is due to proton localization at the backbone amide nitrogen (Reaction 2). Free-acid peptide dications can form zwitterionic structures, liberating a mobile proton that can be located on the polypeptide backbone. That hypothesis is supported by comparison of ECD fragmentation patterns for peptide dications with different C-terminal groups and higher charge state precursor ions. Conversely, zwitterionic structures do not necessarily lead to formation of $a$-ions, as for the cysteic acid derivative. Furthermore, $a$-ion formation can be enhanced at the N-terminal side of proline and is totally eliminated for ECD of sodiated species. Finally, a charged residue at the $\mathrm{N}$-terminus, gas-phase basicity, and charge state (increasing the charge distribution and directing $N$-protonation) are the primary factors that influenced the ability to observe $a$-type fragment ions in this study of polypeptides with less than 12 amino acid residues.

\section{Acknowledgments}

The authors thank Helen Cooper and Søren Bak for providing some synthetic peptides. This work was supported by the NSF National High-Field FT-ICR Mass Spectrometry Facility (DMR-0084173), Florida State University, and the National High Magnetic Field Laboratory at Tallahassee, Florida.

\section{References}

1. Zubarev, R. A.; Kelleher, N. L.; McLafferty, F. W. Electron Capture Dissociation of Multiply Charged Protein Cations. A Nonergodic Process. J. Am. Chem. Soc. 1998, 120(13), 3265-3266.

2. Zubarev, R. A.; Horn, D. M.; Fridriksson, E. K.; Kelleher, N. L.; Kruger, N. A.; Lewis, M. A.; Carpenter, B. K.; McLafferty, F. W. Electron Capture Dissociation for Structural Characterization of Multiply Charged Protein Cations. Anal. Chem. 2000, 72(3), 563-573.

3. Zubarev, R. A. Reactions of Polypeptide Ions with Electrons in the Gas Phase. Mass Spectrom. Rev. 2003, 22(1), 57-77.

4. Budnik, B. A.; Nielsen, M. L.; Olsen, J. V.; Haselmann, K. F.; Horth, P.; Haehnel, W.; Zubarev, R. A. Can Relative Cleavage Frequencies in Peptides Provide Additional Sequence Information?Int. J. Mass Spectrom. 2002, 219(1), 283-294.

5. Cooper, H. J.; Hakansson, K.; Marshall, A. G. The Role of Electron Capture Dissociation in Biomolecular Analysis. Mass Spectrom. Rev. 2005, 24(2), 201-222. 
6. Zubarev, R. A. Electron-Capture Dissociation Tandem Mass Spectrometry. Current Opin. Biotechnol. 2004, 15(1), 12-16.

7. Tsybin, Y. O.; Ramstrom, M.; Witt, M.; Baykut, G.; Hakansson, P. Peptide and Protein Characterization by High-Rate Electron Capture Dissociation Fourier Transform Ion Cyclotron Resonance Mass Spectrometry. J. Mass Spectrom. 2004, 39(7), 719-729.

8. Tsybin, Y. O.; Hakansson, P.; Budnik, B. A.; Haselmann, K. F.; Kjeldsen, F.; Gorshkov, M.; Zubarev, R. A. Improved Low-Energy Electron Injection Systems for High Rate Electron Capture Dissociation in Fourier Transform Ion Cyclotron Resonance Mass Spectrometry. Rapid Commun. Mass Spectrom. 2001, 15(19), 1849-1854.

9. Budnik, B. A.; Haselmann, K. F.; Zubarev, R. A. Electron Detachment Dissociation of Peptide Dianions: An Electron-Hole Recombination Phenomenon. Chem. Phys. Lett. 2001, 342(3/4), 299-302.

10. Kjeldsen, F.; Silivra, O. A.; Ivonin, I. A.; Haselmann, K. F.; Gorshkov, M.; Zubarev, R. A. C $\alpha$-C Backbone Fragmentation Dominates in Electron Detachment Dissociation of Gas-Phase Polypeptide Anions. Chem. Eur. J. 2005, 11, 1803-1812.

11. Bartmess, J. E. Negative ion energetics data; http://webbook.nist.gov/ chemistry/ Gaithersburg, MD, 2003.

12. Summerfield, S. G.; Gaskell, S. J. Fragmentation Efficiencies of Peptide Ions Following Low Energy Collisional Activation. Int. J. Mass. Spectrom. 1997, 165, 509-521.

13. Hakansson, K.; Chalmers, M. J.; Quinn, J. P.; McFarland, M. A.; Hendrickson, C. L.; Marshall, A. G. Combined Electron Capture and Infrared Multiphoton Dissociation for Multistage MS/MS in a Fourier Transform Ion Cyclotron Resonance Mass Spectrometer. Anal. Chem. 2003, 75(13), 3256-3262.

14. Emmett, M. R.; Caprioli, R. M. Micro-Electrospray Mass Spectrometry Ultra-High-Sensitivity Analysis of Peptides and Proteins. J. Am. Soc. Mass Spectrom. 1994, 5(7), 605-613.

15. Guan, S. H.; Marshall, A. G. Stored Waveform Inverse Fourier Transform (SWIFT) Ion Excitation in Trapped-Ion Mass Spectrometry: Theory and Applications. Int. J. Mass Spectrom. Ion Processes 1996, 158, 5-37.

16. McFarland, M. A.; Chalmers, M. J.; Quinn, J. P.; Hendrickson, C. L.; Marshall, A. G. Evaluation and Optimization of Electron Capture Dissociation Efficiency in Fourier Transform Ion Cyclotron Resonance Mass Spectrometry. J. Am. Soc. Mass Spectrom. 2005, 16(7), 1060-1066.

17. Shi, S. D. H.; Drader, J. J.; Freitas, M. A.; Hendrickson, C. L.; Marshall, A. G. Comparison and Interconversion of the Two Most Common
Frequency-to-Mass Calibration Functions for Fourier Transform Ion Cyclotron Resonance Mass Spectrometry. Int. J. Mass Spectrom. 2000, 196, 591-598.

18. Ledford, E. B.: Rempel, D. L.; Gross, M. L. Space-Charge Effects in Fourier-Transform Mass-Spectrometry-Mass Calibration. Anal. Chem. 1984, 56(14), 2744-2748.

19. Blakney, G. T.; Lam, T. T.; Hendrickson, C. L.; Marshall, A. G. FT-ICR MS Data Station for Automated High Speed Data-Dependent Acquisition. Proceedings of the 52nd ASMS Conference on Mass Spectrometry and Allied Topics; Nashville, TN, May 2004.

20. Harrison, A. G. The gas-Phase Basicities and Proton Affinities of Amino Acids and Peptides. Mass Spectrom. Rev. 1997, 16(4), 201-217.

21. http://webbook.nist.gov.

22. Zhang, K.; Zimmerman, D. M.; Chungphillips, A.; Cassady, C. J. Experimental and ab Initio Studies of the Gas-Phase Basicities of Polyglycines. J. Am. Chem. Soc. 1993, 115(23), 10812-10822.

23. Zhang, K.; Cassady, C. J.; Chungphillips, A. Ab Initio Studies of Neutral and Protonated Triglycines-Comparison of Calculated and Experimental Gas-Phase Basicity. J. Am. Chem. Soc. 1994, 116(25), 11512-11521.

24. Breuker, K.; Oh, H. B.; Horn, D. M.; Cerda, B. A.; McLafferty, F. W. Detailed Unfolding and Folding of Gaseous Ubiquitin Ions Characterized by Electron Capture Dissociation. J. Am. Chem. Soc. 2002, 124(22), 6407-6420.

25. Iavarone, A. T.; Paech, K.; Williams, E. R. Effects of Charge State and Cationizing Agent on the Electron Capture Dissociation of a Peptide. Anal. Chem. 2004, 76(8), 2231-2238.

26. Kaltashov, I. A.; Fenselau, C. Thermochemistry of Multiply Charged Melittin in the Gas Phase Determined by the Modified Kinetic Method. Rapid Commun. Mass Spectrom. 1996, 10(7), 857-861.

27. Kaltashov, I. A.; Fenselau, C. C. A Direct Comparison of First and Second Gas-Phase Basicities of the Octapeptide RPPGFSPF. J. Am. Chem. Soc. 1995, 117(39), 9906-9910.

28. Kjeldsen, F.; Adams, C. M.; Silivra, O. A.; Savitski, M. M.; Zubarev, R. A. Localization of Charged Sites and Determination of Their Basicity Order in Gas-Phase Peptide and Protein Cations by Electron Capture Dissociation Source. Proceedings of the 53rd ASMS Conference on Mass Spectrometry and Allied Topics; San Antonio, TX, June, 2005.

29. Kish, M. M.; Ohanessian, G.; Wesdemiotis, C. The Na+ Affinities of $\alpha$-Amino Acids: Side-Chain Substituent Effects. Int. J. Mass Spectrom. 2003, 227(3), 509-524. 